\title{
Metabolizable Energy of Soybean Curd Residue and Its Effective Utilization for Broiler Chick Feed
}

\author{
Prapakorn Tarachai and Koh-en Yamauchi* \\ Laboratory of Animal Science, Faculty of Agriculture, Kagawa \\ University, Miki-cho, Kagawa-ken, 761-0795
}

\begin{abstract}
To estimate the value of metabolizable energy (ME) of soybean curd residue (SCR) (experiment 1 ), a semi-purified diet was substituted by SCR at 0 (CP ; 18.4\%, ME ; 3.39 $\mathrm{kcal} / \mathrm{g}$, Gross energy (GE) ; $4.16 \mathrm{kcal} / \mathrm{g}), 10$ (CP ; 21.0\%, GE ; $4.35 \mathrm{kcal} / \mathrm{g}$ ) and $20 \%$ (CP ; 23.9\%, GE ; $4.48 \mathrm{kcal} / \mathrm{g}$ ) levels. Chromic oxide was mixed with each SCR diet at a $0.3 \%$ level to measure digestibility. A total of 4 Single Comb White Leghorn cockerels of each group were given water and each diet ad libitum for 6 days preliminary adaptation period, then feces from each bird were collected 2 times a day for 4 days. According to the glucose substitution method, ME values of SCR was estimated from the difference between ME of SCR containing diet and ME of reference diet. From this method, ME of SCR was determined as $2.70 \mathrm{kcal} / \mathrm{g}$ DM.

To investigate the effects of dietary SCR on feed intake and body weight gain in broiler chicks (experiment 2), all the diets were formulated to contain same amount of nitrogen $(\mathrm{CP} ; 21.0 \%)$ and energy $(\mathrm{ME} ; 3.00 \mathrm{kcal} / \mathrm{g})$. SCR was included at $0,5,10$ and $15 \%$ levels in mash and pellet forms. Five broiler chicks were given each experimental diet and water ad libitum from 7 to 28 -d-old. Five trials with same protocol were carried out using a total of 200 birds. In mash diets, the feed intake showed a tendency to decrease, but the body weight gain tended to increase with increasing the SCR levels, resulting in improved feed conversion ratio. However, in pellet diets, both feed intake and body weight tended to decrease due to inclusion of SCR, resulting in the impairment of feed conversion ratio. Although feed intakes were higher in each pellet diet than those of mash diets, the body weight gain did not show a definite increase. These results suggest that SCR could be incorporated into broiler chick diets up to $15 \%$ in mash form.
\end{abstract}

Key words : soybean curd residue, metabolizable energy, growth performance, broiler chicks

\section{Introduction}

Soybean curd residue (SCR) is a by-product of tohfu. Since SCR is the residue remained after separation of the hot water-soluble component from the macerated and ground soybeans, it is rich in nutrients (Tarachai et al., 1999). To utilize SCR as a feed source, a silaging method for SCR (Kumai et al., 1993) and a preservation method of ensilaged SCR (Niwa et al., 1995 ; Niwa and Nakanishi, 1997) were examined. In the feeding experiments, significant effect of silaging on the digestibility of crude protein

Received : July 13, 2000 Accepted : December 18, 2000

* Corresponding author ; TEL, FAX : 087-891-3053, E-mail : yamauchi@ag.kagawa-u.ac.jp 
(CP), daily body weight gain and feed conversion ratio were not found in pigs (Niwa and Nakanishi, 1995). In the previous paper, we reported that SCR could be incorporated into the layer chicken diets up to $10 \%$ level (Tarachai et al., 1999). However, we did not determine ME value of SCR and value of SCR as protein source in broiler chicks.

Thus, in experiment $1, \mathrm{ME}$ of SCR was determined using semi-purified diet as a basal diet in layer cockerels. In experiment 2, mash and pellet types of practical feeds containing 0,5, 10 and 15\% SCR were formulated and growth performance, nitrogen utilization and ME in the experimental diets were examined in broiler chicks.

\section{Materials and Methods}

\section{Experiment 1}

\section{Determination of $M E$ in dried $S C R$}

A 12 cockerels of Single Comb White Leghorn (Gallus gallus domesticus) (Julia strain) showing $1.69 \pm 0.04 \mathrm{~kg}$ body weight (mean $\pm \mathrm{SE}$ ) were housed in individual cage in an environmentally-controlled room on a $14-\mathrm{h}$ photoperiod at mean environmental temperature of $20^{\circ} \mathrm{C}$ and relative humidity of $42 \%$. The chickens were allotted into 3 groups, 4 birds of each. The individual cage was designed to separate feces from spilt feed and to collect feces on plastic covered trays. They were adapted to each cage for 2 weeks, and had ad libitum access to water and a commercial layer mash diet (CP ; $17.5 \%$, ME ; $2.83 \mathrm{kcal} / \mathrm{g}$, Nippon Formula Feed Mfg, Co., Ltd., Kanagawa, Japan) before the feeding experiment. The semi-purified diet was formulated to contain $18.4 \% \mathrm{CP}$ and $4.16 \mathrm{kcal} \mathrm{GE} / \mathrm{g}(3.39 \mathrm{kcal} \mathrm{ME} / \mathrm{g})$ as a reference diet as shown in Table 1. The dried SCR was substituted for glucose at 25 and $50 \%$ levels in the reference diet, resulting in 10 and $20 \%$ SCR diets. Chromic oxide $\left(\mathrm{Cr}_{2} \mathrm{O}_{3}\right)$ was mixed with every diet at a level of $0.3 \%$ as an indicator of the determination of digestibility. Feed and water were given ad libitum during experimental period. After a preliminary 6day adaptation feces were collected from each bird 2 times a day for 4 days. The feces were dried at $70^{\circ} \mathrm{C}$ for 3 day, and equilibrated with atmospheric moisture for 2 days prior to the analysis.

\section{Experiment 2}

Feeding experiments of dietary $S C R$

Newly hatched broiler chicks (Marshall Chunky) were obtained from commercial hatchery. They were housed in an electrically heated brooder cage at a temperature of $34^{\circ} \mathrm{C}$ and fed a commercial starter broiler diet (starter G mash, CP ; 23.5\%, ME ; 3.05 kcal/g, Nippon Formula Feed Mfg, Co., Ltd., Kanagawa, Japan) for 7 days. They were then transferred to a cage and allocated to dietary treatments in a temperature controlled room $\left(24^{\circ} \mathrm{C}\right)$. On day 7 , the chicks were weighed individually, and birds having relatively high or low body weights were discarded (initial mean body weight was $133 \mathrm{~g}$ ). In one trial, 40 broiler chicks were allocated to 8 dietary treatments, 5 chicks of each ; 0, 5, 10 and 15\% dietary SCR mash or pellet diet groups. The dried SCR was incorporated in the basal diet, and all the diets were formulated to contain same amount of nitrogen (CP;21.0\%) and energy (ME; $3.00 \mathrm{kcal} / \mathrm{g}$ ) (Table 2). 
Table 1. Ingredients and chemical composition of semi-purified diet

\begin{tabular}{lrrr}
\hline \hline \multirow{2}{*}{ Ingredients, $\%$} & \multicolumn{2}{c}{ Soybean curd residue (SCR) level } \\
\cline { 2 - 4 } & & $10 \%$ & $20 \%$ \\
\hline Glucose & 40.00 & 30.00 & 20.00 \\
Ground corn & 25.90 & 25.90 & 25.90 \\
Fish meal & 8.00 & 8.00 & 8.00 \\
Soybean meal & 20.00 & 20.00 & 20.00 \\
Corn oil & 1.00 & 1.00 & 1.00 \\
SCR & - & 10.00 & 20.00 \\
L-lysine & 0.09 & 0.09 & 0.09 \\
DL-methionine & 0.15 & 0.15 & 0.15 \\
Dicalcium phosphate & 2.00 & 2.00 & 2.00 \\
Sodium chloride & 0.20 & 0.20 & 0.20 \\
Premix* & 0.20 & 0.20 & 0.20 \\
Analytical value (\% of dry matter) & & & \\
Dry matter & 89.90 & 90.28 & 90.62 \\
Gross energy , kcal/g & 4.16 & 4.35 & 4.48 \\
Protein & 18.42 & 20.97 & 23.94 \\
Crude fat & 3.78 & 4.60 & 6.32 \\
Crude fiber & 2.99 & 2.94 & 3.84 \\
Ash & 5.70 & 5.69 & 6.22 \\
\hline
\end{tabular}

* Premix contained : Vitamins ; Vitamin A (8,000 IU), Vitamin $\mathrm{D}_{3}(1,600 \mathrm{IU})$, Acetic acid dl- $\alpha$ - tocopherol $(5.0 \mathrm{mg})$, Menadione sodium bisulfite $(1.6 \mathrm{mg})$, Nitric acid thiamin (1.2 mg), Riboflavin (4.0 mg), Hydrochloric acid pyridoxine (3.6 mg), Cyanocobalamin $(0.01 \mathrm{mg})$, Nicotinic acid $(10.0 \mathrm{mg})$, d-Pantothenic acid $(8.0 \mathrm{mg})$, d-Biotin $(0.05 \mathrm{mg})$, Folic acid $(5.0 \mathrm{mg})$, Choline chloride $(230.4 \mathrm{mg})$, Minerals ; Manganese carbonate $(60.0 \mathrm{mg})$, Zinc carbonate $(50.0 \mathrm{mg})$, Iron sulfate $(81.6 \mathrm{mg})$, Copper sulfate $(12.6 \mathrm{mg})$, Calcium iodate $(0.5 \mathrm{mg})$, Cobalt sulfate $(0.3 \mathrm{mg})$.

The diet was kept as mash form and the remaining half was pelleted by meat chopper equipped with a die of 3-mm diameter. Feeding experiments for each diet were performed from 7 to 28 -d-old, and feed intake and body weight gain were measured. With regard to pellet groups, the pellet was fed in a crumble form during 7 to 14-d-old followed by a conventional pellet. Five trials with same protocol were carried out using a total of 200 birds. Feed and water were allowed ad libitum.

From 21 to 25 days of age, the experimental diets containing $\mathrm{Cr}_{2} \mathrm{O}_{3}$ were fed to determine digestibilities of energy and nitrogen. The $\mathrm{Cr}_{2} \mathrm{O}_{3}$ was mixed thoroughly before pelleting at a level of $0.3 \%$ and the diets containing the indicator were given to chicks. The feces were collected 2 times a day by the plastic covered tray on day 24 and 25. The wet feces in each group was dried at $70^{\circ} \mathrm{C}$ for $2-3$ days and then equilibrated with atmospheric moisture for 2 days prior to the analysis.

All experiments were performed according to the humane care guidelines provided by the Faculty of Agriculture at Kagawa University. 
Table 2. Ingredients and chemical composition of experimental diets

\begin{tabular}{|c|c|c|c|c|c|c|c|c|}
\hline \multirow{2}{*}{\multicolumn{2}{|c|}{ Ingredients }} & \multicolumn{7}{|c|}{ Soybean curd residue (SCR) level, \% } \\
\hline & & \multicolumn{2}{|l|}{0} & 5 & \multicolumn{2}{|r|}{10} & \multicolumn{2}{|c|}{15} \\
\hline Ground corn & \multicolumn{2}{|r|}{60.80} & & 58.84 & \multicolumn{2}{|c|}{55.30} & \multicolumn{2}{|c|}{53.10} \\
\hline Rice bran & \multicolumn{2}{|r|}{3.00} & & 3.00 & \multicolumn{2}{|c|}{3.00} & \multicolumn{2}{|c|}{3.00} \\
\hline Fish meal & \multicolumn{2}{|r|}{6.00} & & 6.00 & \multicolumn{2}{|c|}{6.00} & \multicolumn{2}{|c|}{6.00} \\
\hline Soybean meal & \multicolumn{2}{|r|}{25.00} & & 20.00 & \multicolumn{2}{|c|}{15.00} & \multicolumn{2}{|c|}{10.00} \\
\hline Corn gluten & \multicolumn{2}{|r|}{-} & & 2.50 & \multicolumn{2}{|c|}{5.00} & \multicolumn{2}{|c|}{7.00} \\
\hline Corn oil & \multicolumn{2}{|r|}{2.00} & & 2.00 & \multicolumn{2}{|c|}{2.50} & \multicolumn{2}{|c|}{2.70} \\
\hline SCR & \multicolumn{2}{|r|}{-} & & 5.00 & \multicolumn{2}{|c|}{10.00} & \multicolumn{2}{|c|}{15.00} \\
\hline L-lysine & & 0.09 & & 0.11 & \multicolumn{2}{|c|}{0.12} & \multicolumn{2}{|c|}{0.14} \\
\hline \multicolumn{2}{|l|}{ DL-methionine } & 0.15 & & 0.12 & \multicolumn{2}{|c|}{0.10} & \multicolumn{2}{|c|}{0.09} \\
\hline \multicolumn{2}{|c|}{ Dicalcium phosphate } & 2.50 & & 2.50 & \multicolumn{2}{|c|}{2.50} & 2 . & 50 \\
\hline Sodium chloride & & 0.25 & & 0.25 & & 25 & & 25 \\
\hline Premix* & & 0.20 & & 0.20 & & 20 & & 20 \\
\hline Analytical value & of $d r y$ & matter) & & & & & & \\
\hline & Mash & Pellet & Mash & Pellet & Mash & Pellet & Mash & Pellet \\
\hline Dry matter & 88.29 & 91.95 & 88.54 & 93.13 & 89.05 & 93.25 & 88.91 & 93.24 \\
\hline $\mathrm{GE}, \mathrm{kcal} / \mathrm{g}$ & 4.42 & 4.42 & 4.48 & 4.55 & 4.56 & 4.60 & 4.63 & 4.68 \\
\hline Protein & 22.86 & 22.14 & 21.71 & 22.04 & 23.20 & 23.51 & 23.10 & 22.61 \\
\hline Crude fat & 4.65 & 5.79 & 6.26 & 6.92 & 7.54 & 7.37 & 8.46 & 8.49 \\
\hline Crude fiber & 2.46 & 2.50 & 2.99 & 3.02 & 3.34 & 3.33 & 3.68 & 3.54 \\
\hline Ash & 6.64 & 7.01 & 6.73 & 7.18 & 6.71 & 6.89 & 6.47 & 6.65 \\
\hline Weight/volume & 0.50 & 0.53 & 0.48 & 0.52 & 0.45 & 0.51 & 0.43 & 0.51 \\
\hline
\end{tabular}

* Premix contents see Table 1 .

Analytical methods of Nutrients and $M E$ in broiler diets

Dry matter, CP, crude fat, crude fiber, and ash were determined using the method described by Association of Official Analytical Chemists (1965) and bulk density of the diets were determined using $1,000 \mathrm{~m} l$ cylender. The gross energy of dried feces and diets were measured using a bomb calorimeter (C5000, IKA Werke, Janke L., Kunkel GmbH L Co. KG., Germany). Chromic oxide was analyzed as described by Bolin et al., (1952).

The ME of experimental diets and SCR were calculated according to the methods of Anderson et al., (1958) and Hill et al., (1960), as follows.

$\mathrm{ME}(\mathrm{kcal} / \mathrm{g}$ diet $)=$ Energy per gram diet - Feces energy per gram $\operatorname{diet}-8.22 \times \mathrm{N}$ retained per gram diet.

Feces energy per gram diet $=$ Energy per gram feces $\times \frac{\% \mathrm{Cr}_{2} \mathrm{O}_{3} \text { in diet }}{\% \mathrm{Cr}_{2} \mathrm{O}_{3} \text { in feces }}$

$N$ retained per gram diet $=N$ per gram diet $-N$ per gram feces $\times \frac{\% \mathrm{Cr}_{2} \mathrm{O}_{3} \text { in diet }}{\% \mathrm{Cr}_{2} \mathrm{O}_{3} \text { in feces }}$ 
Computation of ME of SCR was made as follows : $\mathrm{ME}$ of SCR $(\mathrm{kcal} / \mathrm{g})=3.007-\frac{\text { ME per gram reference diet }- \text { ME per gram test diet }}{\text { Proportion of substituted ingredient }}$

A metabolizable energy of $3.077 \mathrm{kcal} / \mathrm{g}$ was used in the calculations for glucose (estimated $97 \%$ of determined gross energy ; Anderson et al., 1958). All values were expressed on dry matter basis.

From experiment 1 and 2, nitrogen utilization was calculated as follows ;

Nitrogen utilization, $\%=100-\left(100 \times \frac{\% \mathrm{Cr}_{2} \mathrm{O}_{3} \text { in diet }}{\% \mathrm{Cr}_{2} \mathrm{O}_{3} \text { in feces }} \times \frac{\% \text { nitrogen in feces }}{\% \text { nitrogen in diet }}\right)$

\section{Statistical Analysis}

The statistical analysis was performed with Stat View program (Abacus Concepts, Inc.) using the two-way ANOVA procedure, and significant differences among treatments were determined with Duncan's multiple range test at the level of $\mathbf{P}<0.05$.

\section{Results}

\section{Experiment 1}

$M E$ of dried SCR

Chemical compositions of the semi-purified diets and the experimental diets are shown in Table 1 and 2, respectively. After feeding the semi-purified diet for 10 days, feed intake was 99.0 $\pm 5.2,85.4 \pm 6.4$ and $82.2 \pm 6.5 \mathrm{~g} /$ day/bird (mean $\pm \mathrm{SE}$ ) in reference diet, 10 and $20 \%$ SCR diets, respectively. The respective body weight gains were $150 \pm 4.6,155 \pm 6.3$ and $125 \pm 6.7 \mathrm{~g}$. The nitrogen utilization and ME of the semipurified diets and the SCR diets are shown in Table 3. Both parameters were significantly decreased with increasing SCR level $(P<0.05)$. The ME of SCR in 10 and $20 \%$ SCR diets were $2.67 \mathrm{kcal} / \mathrm{g} \mathrm{DM}$ and $2.72 \mathrm{kcal} / \mathrm{g} \mathrm{DM}$, respectively. As these ME values were not significantly different, the average ME value $(2.70 \mathrm{kcal} / \mathrm{g} \mathrm{DM})$ was determined as the ME value of SCR. Similarly, the percentage of ME per gross energy was estimated as $49.6 \%$.

Experiment 2

Broiler performance

Table 3. Nitrogen utilization and metabolizable energy (ME) of the reference diet and diets containing soybean curd residue (SCR)

\begin{tabular}{|c|c|c|c|c|}
\hline $\begin{array}{c}\text { Substitution } \\
\text { level (\% of DM) }\end{array}$ & N-utilization & \multicolumn{2}{|l|}{ ME of diet } & $\mathrm{ME}$ of SCR \\
\hline & $-\%$ & \multicolumn{2}{|c|}{$-\mathrm{kcal} / \mathrm{g}$} & $-\%$ of $\mathrm{GE}-$ \\
\hline 0 (Reference) & $57.2 \pm 2.3 \mathrm{a}$ & $3.39 \pm 0.02 \mathrm{a}$ & & \\
\hline 25 & $39.8 \pm 3.5 \mathrm{~b}$ & $3.28 \pm 0.04 \mathrm{ab}$ & $2.67 \pm 0.14$ & $49.2 \pm 2.6$ \\
\hline 50 & $32.7 \pm 2.3 \mathrm{~b}$ & $3.20 \pm 0.05 \mathrm{~b}$ & $2.72 \pm 0.08$ & $50.1 \pm 1.7$ \\
\hline
\end{tabular}

$\mathrm{GE}=$ Gross energy.

Value are means \pm SE of 4 birds.

Means having different superscripts within the same column are significantly different at $\mathrm{P}<0.05$. 
Table 4. Effects of dietary SCR levels on feed intake, body weight gain and feed conversion ratio of broiler chick during 7 to 28 -d-old

\begin{tabular}{lccccc}
\hline \hline \multicolumn{1}{c}{ Form } & Level $(\%)$ & $\begin{array}{c}\text { Feed intake } \\
(\mathrm{g} / \mathrm{bird})\end{array}$ & $\begin{array}{c}\text { Feed intake } \\
(\mathrm{m} l / \text { bird })\end{array}$ & $\begin{array}{c}\text { BWG } \\
(\mathrm{g} / \mathrm{bird})\end{array}$ & FCR \\
\hline \multirow{3}{*}{ Mash } & 0 & $1,150 \pm 65$ & $2,296 \pm 130$ & $760 \pm 14 \mathrm{ab}$ & $1.51 \pm 0.09$ \\
& 5 & $1,146 \pm 75$ & $2,373 \pm 155$ & $800 \pm 15 \mathrm{a}$ & $1.44 \pm 0.10$ \\
& 10 & $1,074 \pm 66$ & $2,386 \pm 146$ & $775 \pm 20 \mathrm{a}$ & $1.39 \pm 0.11$ \\
& 15 & $1,106 \pm 50$ & $2,589 \pm 117$ & $778 \pm 26 \mathrm{a}$ & $1.43 \pm 0.08$ \\
Pellet & 0 & $1,300 \pm 91$ & $2,462 \pm 173$ & $843 \pm 26 \mathrm{a}$ & $1.53 \pm 0.06$ \\
& 5 & $1,273 \pm 82$ & $2,462 \pm 158$ & $797 \pm 48 \mathrm{a}$ & $1.60 \pm 0.02$ \\
& 10 & $1,258 \pm 84$ & $2,460 \pm 165$ & $806 \pm 34 \mathrm{a}$ & $1.56 \pm 0.09$ \\
Significance level & 15 & $1,178 \pm 127$ & $2,324 \pm 250$ & $686 \pm 36 \mathrm{~b}$ & $1.70 \pm 0.11$ \\
Level & & & & & \\
Form & & $\mathrm{NS}$ & $\mathrm{NS}$ & $\mathrm{NS}$ & $\mathrm{NS}$ \\
Level $\times$ Form & & $*$ & $\mathrm{NS}$ & $\mathrm{NS}$ & $*$ \\
\hline
\end{tabular}

Values are mean $\pm \mathrm{SE}$ of 5 groups.

Means having different superscripts within the same column are significantly different at $\mathrm{P}<0.05$.

$B W G=$ Body weight gain.

$\mathrm{FCR}=$ Feed conversion ratio

$\mathrm{NS}=$ no significant different.

*= significance different at $\mathrm{P}<0.05$.

** = significance different at $\mathrm{P}<0.01$.

Table 4 shows the feed intake, body weight and feed conversion ratio of chicks fed SCR diets of mash or pellet form during 7 to 28 -d-old. Total weight and volume of feed consumed tended to decrease with increasing SCR levels in both diet groups. However, when the mash diet was given, the body weight gain tended to increase, whereas that of the pellet group tended to decrease, resulting in improved feed conversion ratio in the mash group but not in the pellet group. Weight and volume of feed intake of the pellet group was higher than mash group. Feed conversion ratio of the pellet group was significantly higher than that of the mash group.

Nitrogen utilization and ME of SCR

Table 5 shows nitrogen utilization and ME of SCR diets of mash or pellet form. Nitrogen utilization tended to be decreased by feeding SCR in both diet forms and the pellet groups showed a significant lower value than the mash group. ME of the diets were not significantly affected by SCR and diet forms.

\section{Discussion}

The aims of this study were to determine the ME value of SCR and to examine the possibility of utilizing SCR as a feed source for broiler chicken. According to the ME calculating methods described by Anderson et al. (1958) and Hill et al. (1960) ME 
Table 5. Effect of dietary SCR levels on nitrogen excretion, nitrogen utilization and ME content during 21-25-d-old (calculated on dry matter basis)

\begin{tabular}{|c|c|c|c|c|c|c|}
\hline Form & $\begin{array}{l}\text { Level } \\
(\%)\end{array}$ & $\underset{(\%)^{1}}{\operatorname{Dietary} N}$ & $\begin{array}{c}\text { N-excretion } \\
(\%)^{2}\end{array}$ & $\underset{(\%)}{\text { N-utilization }}$ & $\begin{array}{c}\mathrm{ME} \\
\text { (kcal/g) }\end{array}$ & $(\%$ of $\mathrm{GE})$ \\
\hline \multirow{4}{*}{ Mash } & 0 & 3.66 & $1.25 \pm 0.72 \mathrm{c}$ & $65.8 \pm 2.0 \mathrm{a}$ & $3.17 \pm 1.12$ & $71.6 \pm 1.1$ \\
\hline & 5 & 3.47 & $1.56 \pm 0.13 \mathrm{bc}$ & $55.2 \pm 3.8 \mathrm{abc}$ & $3.08 \pm 0.03$ & $68.8 \pm 0.6$ \\
\hline & 10 & 3.71 & $1.60 \pm 0.10 \mathrm{bc}$ & $57.0 \pm 2.7 \mathrm{ab}$ & $3.14 \pm 0.01$ & $68.9 \pm 0.3$ \\
\hline & 15 & 3.70 & $1.48 \pm 0.06 \mathrm{bc}$ & $60.0 \pm 1.6 \mathrm{a}$ & $3.27 \pm 0.05$ & $70.6 \pm 1.1$ \\
\hline \multirow{4}{*}{ Pellet } & 0 & 3.47 & $1.89 \pm 0.13 \mathrm{ab}$ & $46.7 \pm 3.7 \mathrm{bcd}$ & $3.06 \pm 0.03$ & $69.1 \pm 0.6$ \\
\hline & 5 & 3.53 & $2.08 \pm 0.13 \mathrm{a}$ & $41.1 \pm 3.8 \mathrm{~d}$ & $3.12 \pm 0.06$ & $68.6 \pm 1.4$ \\
\hline & 10 & 3.76 & $2.14 \pm 0.14 \mathrm{a}$ & $43.0 \pm 3.7 \mathrm{~cd}$ & $3.08 \pm 0.07$ & $66.9 \pm 1.6$ \\
\hline & 15 & 3.62 & $2.04 \pm 0.27 \mathrm{a}$ & $43.7 \pm 7.4 \mathrm{~cd}$ & $3.17 \pm 0.13$ & $67.8 \pm 2.8$ \\
\hline \multicolumn{7}{|c|}{ Significance level } \\
\hline \multicolumn{3}{|l|}{ Level } & NS & NS & NS & NS \\
\hline \multicolumn{3}{|l|}{ Form } & $* *$ & $* *$ & NS & NS \\
\hline \multicolumn{3}{|c|}{ Level $\times$ Form } & NS & NS & NS & NS \\
\hline
\end{tabular}

Values are means \pm SE of 4 groups.

Mean of having different superscripts within the same parameter are significantly different at $\mathrm{P}<0.05$.

$1=\mathrm{CP} / 6.25$.

${ }^{2}=$ Nitrogen in feces plus uric acid.

$\mathrm{NS}=$ no significant different.

**= significance at $\mathrm{P}<0.01$.

value of SCR was determined as $2.70 \mathrm{kcal} / \mathrm{g} \mathrm{DM}$. The CP and amino acids in SCR (Tarachai et al., 1999) are almost half of those in the soybean meal (NRC, 1994 ; Mekbungwan et al., 1999) but the crude fat (15.3\%) and crude fiber (16.9\%) are 15 times and 2 times higher than those of the soybean meal, respectively. The ME of SCR is about $0.4 \mathrm{kcal} / \mathrm{g}$ higher than the values of soybean meal shown by NRC (1994) and in the standard tables of feed composition in Japan (1995). This may be caused by the higher percentage of crude fat in SCR than that of soybean meal. Chemical composition of SCR described previously (Tarachai et al., 1999) and the present ME of SCR demonstrate that nutritive value of SCR is high as a chicken feed source.

The feed intake tended to decrease with increasing SCR levels. This is consistent with the results of laying hens fed conventional diet mixed with SCR (Tarachai et al., 1999). This might be induced by physical features of SCR such as bulk density (weight per volume) and high water-absorptive power. The satiety center in the hypothalamus may be stimulated in response to the physical features of SCR. Besides, high crude fat content of SCR is thought to decrease feed consumption. It is known that unsaturated fatty acid in soybean oil is metabolically more efficient than that of saturated fatty acid (Atteh and Leeson, 1984 ; Leeson and Atteh, 1995). Thus, turkey poults fed diets containing soybean oil showed the decreased feed intake than that of the control (Leeson and Atteh, 1995). Feed passage rate through the intestine was also 
lowered with increasing the fat supplement levels (Mateos et al., 1982). These facts lead us to postulate the idea that the feed intake would be decreased with increasing SCR levels.

The nitrogen utilization tended to be decreased by feeding SCR diets. This is in harmony with results that dietary protein utilization of broilers fed the 5\% SCR diet significantly decreased (Park and Song, 1996). These results might be induced by high crude fiber content in SCR. The dietary fiber is known to absorb the digestive enzyme such as protease secreted into the intestinal lumen, resulting in the increase of endogenous nitrogen in feces (Shah et al., $1982 ; 1986$ ).

In spite of the decreased feed intake, body weight gain tended to increase after feeding the mash form SCR diet, demonstrating the high nutritive value of SCR. Improved feed conversion ratio after feeding 15\% SCR diet suggests that SCR could be incorporated for the broiler chick diet up to $15 \%$ in mash form. As the price of the dried SCR (about 30 yen per $\mathrm{kg}$ ) is lower than that of soybean meal (about 52 yen), utilization of SCR as a protein source for chicken diet can contribute to the reduction of the feed cost in chicken production.

When dried SCR powder was added into the practical diet, the bulk density is thought to influence feed intake. To overcome this problem, pelleted SCR diets were also prepared. Pelleting is known to elevate the bulk density, size and hardness of feed particles, and reduces the amount of dust (Nir et al., 1994). Feed intake, body weight gain and feed conversion ratio are known to be improved by pelleting (Zatari and Sell, 1990 ; Savory, 1974 ; Nir et al., 1994 ; Bustany, 1996). However, in the present study, feed conversion ratio was not improved in the pellet groups. As the benefit of pellet diet depends on its hardness (Nir et al., 1994) and on grinding method of grain (Nir et al., 1995), further experiments are needed to improve the pellet.

In conclusion, we estimated the ME value of dried SCR as $2.70 \mathrm{kcal} / \mathrm{g} \mathrm{DM}$, and SCR could be incorporated into broiler chick diets up to $15 \%$ in mash form.

\section{Reference}

Anderson DL, Hill FW and Renner R. Studies of the metabolizable and productive energy of glucose for the growing chick. Journal of Nutrition, $65: 561-574.1958$.

Association of Official Analytical Chemists. In 'Methods of analysis (Association of Official Analytical Chemists.)' $14^{\text {th }}$ ed., pp 328-334. Washington, DC. 1965.

Atteh JO and Leeson S. Effects of dietary saturated or unsaturated fatty acids and calcium levels on performance and mineral metabolism of broiler chicks. Poultry Science, $63: 2252-2260$. 1984.

Bolin DW, King RP and Klosterman EW. A simplified method for determination of chromic oxide $\left(\mathrm{Cr}_{2} \mathrm{O}_{3}\right)$ when used as an index substance. Science, $116: 634-635.1952$.

Bustany ZA. The effect of pelleting an enzyme-supplemented barley-based broiler diet. Animal Feed Science Technology, $58: 283-288.1996$.

Hill FW, Anderson DL, Renner R and Carew LB. Studies of the metabolizable energy of grain and grain products for chickens. Poultry Science, $39: 573-579.1960$.

Kumai S, Ootsu N, Fukumi R, Hattori I, Ueda H, Inokuchi K, Sawada K and Izumi K. The fermentation quality of silaged okara inducing the beet pulp for beef cattle feed and the feed value of silaged okara. Bulletin of the Experimental Farm, College of Agriculture, Ehime Univerity, $14: 29-33.1993$. (in Japanese). 
Leeson S and Atteh JO. Utilization of fats and fatty acids by turkey poults. Poultry Science, 74 : 2003-2010. 1995.

Mateos GG, Sell JL and Eastwood JA. Rate of food passage (transit time) as influenced by level of supplemental fat. Poultry Science, $61: 94-100.1982$.

Mekbungwan A, Yothinsirikul W, Thongwittaya N and Yamauchi K. Effects of dietary pigeon pea (Cajanus cajan L.) seed meal on growth performance in piglets and growing pigs. Animal Science Journal, 70 : 201-206. 1999.

National Research Council. Nutrient requirements of poultry $9^{\text {th }}$ ed. National Acadimic Press, Washington, DC. 1994.

Nir I, Hillel R, Ptichi I and Shefet G. Effect of particle size on performance. 3. Grinding pelleting interactions. Poultry Science, 74 : 771-783. 1995.

Nir I, Twina Y, Grossman E and Nitsan Z. Quantitative effects of pelleting on performance, gastrointestinal tract and behaviour of meat-type chickens. British Poultry Science, 35 : 589602. 1994.

Niwa Y, Kamata $\mathbf{H}$ and Nakanishi G. Effect of Aspergillus sojae and cellulase preparations on tofu cake fermentation characteristics. Animal Science and Technology, $66: 79-85.1995$. (in Japanese).

Niwa $\mathrm{Y}$ and Nakanishi G. Research nitrogen utilization of food by-product to growing and finishing pigs : 2 . The effects of tofu cake silage feeding on growth and body fat. Japanese Journal of Swine Science, $32: 1-7.1995$. (in Japanese).

Niwa Y and Nakanishi G. Characteristics of tofu cake preserved with Aspergillus sojae or celluase preparation. Animal Science and Technology, $68: 82-95$. 1997. (in Japanese).

Park JH and Song YH. The effects of dried soybean curd residue supplementation on the performance of broilers and layers. Korean Journal of Animal Science, 38 : 205-214. 1996. (in Korean).

Savory CJ. Growth and behaviour of chicks fed on pellets or mash. British Poultry Science, $15: 281-286.1974$.

Shah N, Atallah MT, Mahoney RR and Pellett PL. Effect of dietary fiber components on fecal nitrogen excretion and protein utilization in growing rats. Journal of Nutrition, $112: 658$ 666. 1982.

Shah M, Mahoney RR and Pellett PL. Effect of guar gum, lignin and pectin on proteolytic enzyme levels in the gastrointestinal tract of rat : A time-based study. Journal of Nutrition. $116:$ 786-794. 1986.

Standard Tables of Feed Composition in Japan. Agriculture, Forestry and Fisheries Research Council Secretariat, Ministry of Agriculture, Forestry and Fisheries. Central Association of Livestock Industry, Tokyo. 1995.

Tarachai P, Thongwittaya N, Kamisoyama $\mathbf{H}$ and Yamauchi K. Effective utilization of soybean curd residue for chicken feed as a plant protein source. Japanese Poultry Science, 36 : 311318. 1999.

Zatari IM and Sell JL. Effects of pelleting diets containing sunflower meal on the performance of broiler chickens. Animal Feed Science and Technology, $30: 121-129.1990$. 